\title{
A CODIFICAÇÃO DAS RELAÇÕES GRAMATICAIS NOS COMPLEMENTOS ORACIONAIS DO APINAJE
}

Christiane Cunha de Oliveira*

\section{RESUMO}

A codificação das relações gramaticais nas línguas da família Jê apresenta grande riqueza morfossintática que se manifesta nas orações simples e que se amplia ainda mais nos contextos de subordinação. Em Apinaje, a marcação argumental nas orações principais exibe um padrão nominativo, expresso através de pronomes, e absolutivo, expresso pelos prefixos pessoais. Em verbos de marcação argumental não canônica, argumentos centrais são marcados por posposições oblíquas; dentre estes, encontram-se os verbos que recebem complementos oracionais. Nesse contexto de subordinação, o alinhamento ergativo se manifesta, sendo determinado pelas condições de correferencialidade entre os sujeitos da oração principal e da subordinada.

Palavras-chave: Apinaje, categoria de pessoa, relações gramaticais, complementos oracionais.

\section{INTRODUÇÃO}

Este trabalho ${ }^{1}$ tem por objetivo desenvolver uma análise das relações gramaticais da língua Apinaje $^{2}$ em orações simples e em complementos oracionais, partindo da compreensão do funcionamento do sistema de marcação pessoal da língua. Os fundamentos teóricos que embasam esta pesquisa têm suas raízes nos estudos tipológicos acerca dos sistemas de codificação das relações gramaticais nas línguas do mundo, bem como nos estudos funcionalistas para a compreensão dessas relações a partir de fatores discursivo-pragmáticos e diacrônicos, tais como Givón (2001), Noonan (2007), Dixon e Aikhenvald (2000), dentre outros.

* Doutora em Linguística pela Universidade do Oregon (EUA). Professora da Faculdade de Letras da Universidade Federal de Goiás, Goiânia, Goiás, Brasil.

E-mail: christianedeoliveira@ufg.br 
A primeira seção do artigo apresenta os detalhes do sistema de marcação pessoal da língua; a segunda seção trata da categorização dos verbos do Apinaje conforme critérios semânticos e morfossintáticos; a terceira seção discute as formas não finitas dos verbos em Apinaje; e a quarta seção aborda a forma de codificação das relações gramaticais em construções envolvendo complementos oracionais. Ao final, algumas conclusões são alcançadas, levando-se em conta especialmente a relevância da não finitude para a manifestação morfossintática da ergatividade na língua Apinaje. ${ }^{3}$

\section{O SISTEMA DE MARCAÇÃo DE PESSOA}

O sistema de marcação pessoal na língua Apinaje dispõe de pronomes independentes e de prefixos pessoais, os quais codificam as distinções de primeira, segunda e terceira pessoas (1a-d). Distinções de número dual e plural são expressas por clíticos que atendem tanto a um quanto a outro conjunto de morfemas $(1 \mathrm{c}-\mathrm{g}){ }^{4}$

$\begin{array}{llll}\text { a. } & \text { na } & p a & \text { a-kapi }^{5} \\ \text { RLS } & 1 & 2 \text {-escolher }\end{array}$

'Eu escolhi você.'

b.

$\begin{array}{lll}\text { na } & k a & \text { itf-kapi } \\ \text { RLS } & 2 & 1 \text {-escolher }\end{array}$

'Você me escolheu.'

$\begin{array}{lllll}\text { c. } & \text { na } & p a & {[\underline{\text { mẽ }}} & \underline{\varnothing}] \text {-kapi } \\ \text { RLS } & 1 & \text { PL } & \text { 3-escolher }\end{array}$

'Eu os escolhi.'

d. na $\left[\begin{array}{ll}\varnothing & m \tilde{e}\end{array} \quad \underline{\mathrm{it} f}-\mathrm{kapi}\right.$

RLS 3 PL 1-escolher

'Eles me escolheram.'

e. na $\left[\begin{array}{ll}k a & m \tilde{e}\end{array}\right] \quad\left[\begin{array}{ll}\text { va } & \varnothing]-k a p i\end{array}\right.$

RLS 2 PL DU 3-escolher

'Vocês (plural) os escolheram (dual).' 
$\begin{array}{llllll}\text { f. } & \text { na } & p a & {[\underline{\mathrm{va}}} & \underline{\text { a] }} \text {-mə̃ } & \text { ku-gõ } \\ & \text { RLS } & 1 & \text { DU } & \text { 2-DAT } & \text { 3-dar }\end{array}$

'Eu dou (algo) a vocês (dual).'

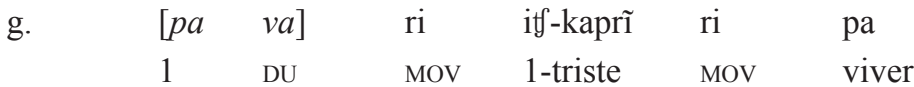

'Nós (duas) andamos tristes por aí.'

Constituintes em primeira pessoa dual podem manifestar as distinções de perspectiva inclusiva ou exclusiva, codificada no Apinaje através da alternância entre o uso do pronome independente ou do prefixo pessoal acompanhado do clítico numeral. Na perspectiva inclusiva, o número dual engloba os participantes do discurso - primeira e segunda pessoas (2a), enquanto na perspectiva exclusiva, o dual exclui a segunda, englobando assim a primeira e a terceira pessoas (2b).
a.

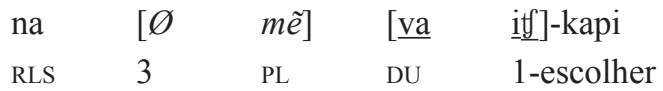

'Eles nos escolheram (dual inclusivo).'

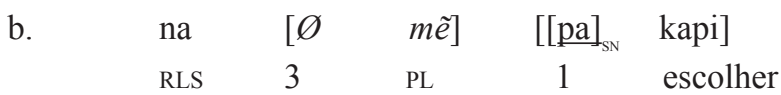

'Eles nos escolheram (dual exclusivo).'

Os dados analisados sugerem que a manifestação gramatical dessa distinção se dá somente em posição adjacente ao verbo, sendo que o pronome independente de primeira pessoa se comporta, nesse contexto, como um sintagma nominal dependente, um clítico verbal. A outra peculiaridade é que aparentemente o morfema $p a$ só pode expressar a distinção de número quando ocorre nessa posição sintática.

Os dados sugerem ainda que a perspectiva exclusiva pode ser expressa também no plural, desde que o pronome independente $p a$ venha acompanhado do clítico mẽ, indicativo de plural (3b). Note-se que a distribuição do marcador de plural em relação ao pronome é idêntica à sua distribuição relativamente aos prefixos pessoais, nesta mesma posição sintática. 
O morfema de primeira pessoa $p u$ também invoca a noção de número e é bastante usado em situações hortativas, embora não se restrinja a elas. Parece plausível analisá-lo como um marcador "coletivo" de primeira pessoa (3).
a. $\quad p u j$
[mẽ akũdo]
1.CLT.IRLS PL sumir $^{7}$
'Vamos sumir!'
b. $\quad p u$
1.CLT
$\begin{array}{cll}{\left[\begin{array}{ll}\underline{\mathrm{me}} & \text { pa }\end{array}\right]} & \mathrm{kag} \rho \\ \mathrm{PL} & 1 & \text { molhado }\end{array}$
pa
CMPL
'Nós nos molhamos todos (plural exclusivo).'

À exceção dos pronomes pa/paj e $p u / p u j$, então, as distinções gramaticais codificadas pelos demais morfemas se restringem unicamente à categoria de pessoa.

Além desses contrastes, o sistema de pessoa da língua Apinaje expressa as relações gramaticais entre os participantes do evento codificado na oração, caracterizando-se morfossintaticamente por uma cisão entre dois padrões de alinhamento: o nominativo e o absolutivo.

Os pronomes independentes manifestam o padrão nominativo e constituem a primeira evidência em favor da categoria gramatical de sujeito na língua. A ocorrência do pronome independente, nos dados, é obrigatória nas orações transitivas e nas intransitivas que envolvem verbos ativos. Já nas orações intransitivas envolvendo verbos descritivos, a ocorrência dos pronomes independentes é opcional.

Os prefixos pronominais, por outro lado, manifestam o padrão absolutivo. Nas orações transitivas, enquanto o pronome livre codifica A, o prefixo pessoal codifica $\mathrm{O}(4 \mathrm{a})$. Nas orações intransitivas, haverá a ausência obrigatória do prefixo nos verbos ativos (4b) e a sua presença obrigatória nos verbos descritivos (4c). Assim, nas orações intransitivas ativas, o pronome será o único índice de pessoa, codificando $\mathrm{S}_{\mathrm{A}}$, enquanto nas orações descritivas, $\mathrm{S}_{\mathrm{o}}$ será codificado pelo prefixo de pessoa no verbo, podendo coocorrer com o pronome, cuja presença é opcional nesses contextos. 
(4)

a. na $k a \quad \underline{\text { itf }- \text { pĩ }}$

RLS 2 1-matar

'Você me mata.'

b. kst kaj gr\&

IRLS 2.IRLS dançar

'Você vai dançar.'

$\begin{array}{llll} & & (\mathrm{S}) & \underline{\mathrm{S}}-\mathrm{V} \\ \text { c. } & \text { na } & (k a) & \underline{\mathrm{a}}-\mathrm{j}-\mathrm{akr} \dot{1} \\ & \text { RLS } & 2 & \text { 2-PR-frio } \\ & \text { 'Você está fria.' }\end{array}$

$\mathrm{O}$ alinhamento entre o argumento A das orações transitivas com o argumento $\mathrm{S}_{\mathrm{A}}$ das orações intransitivas ativas, expressos pelos pronomes independentes, revela o padrão nominativo de organização sintática nas orações principais (4a-b), enquanto o alinhamento entre o argumento $\mathrm{O}$ das orações transitivas com o argumento $\mathrm{S}_{\mathrm{o}}$ das orações intransitivas descritivas, expressos pelos prefixos pessoais, revela $o$ padrão absolutivo (4a-c).

Os morfemas indicadores de pessoa do Apinaje são apresentados na tabela abaixo. Os prefixos pessoais são usados em nomes, verbos e posposições, exceto o marcador genitivo de terceira pessoa, $i$-, restrito aos nomes, e o marcador acusativo de terceira pessoa, $\mathrm{ku}$-, que ocorre somente nos verbos transitivos, como veremos adiante.

Tabela 1 - Índices de pessoa em Apinaje

\begin{tabular}{|l|l|c|c|c|c|}
\cline { 3 - 6 } \multicolumn{2}{c|}{} & $1^{\mathrm{a}}$ pessoa & $1^{\mathrm{a}}$ coletivo & $2^{\mathrm{a}}$ pessoa & $3^{\mathrm{a}}$ pessoa \\
\hline \multirow{3}{*}{ PRONOMES } & REALIS & $p a$ & $p u$ & $k a$ & $\varnothing$ \\
\cline { 2 - 6 } & IRREALIS & $p a j$ & $p u j$ & $k a j$ & $j a$ \\
\hline \multirow{3}{*}{ PREFIXOS } & & $i C-^{8}$ & & $a-$ & $\varnothing-$ \\
\cline { 2 - 6 } & & & & & $k u-$ \\
\cline { 2 - 6 } & & & & & $i-$ \\
\hline
\end{tabular}


A forma dos pronomes é condicionada pela distinção de modo - realis ou irrealis, que é codificada na oração por clíticos de posição inicial - na e $k s t$, respectivamente. Como se nota na Tabela 1 , há duas séries de pronomes pessoais cujas ocorrências são determinadas pelas distinções de modo. Os pronomes da série irrealis se caracterizam pela presença do segmento $/ \mathrm{j} /$, contrastando, assim, com os pronomes da série realis, caracterizados pela sua ausência. ${ }^{9}$

O segmento palatal observado nas formas de primeira e segunda pessoa da série irrealis pode ser analisado como um sufixo, já que a ocorrência dessas formas pronominais, independentemente da presença do morfema $k$ t na oração, não só é possível como parece suprir a necessidade de codificação da categoria de modo, em certos contextos. Dessa forma, pode-se entender que há apenas uma série básica de pronomes e seus alomorfes, cuja distribuição é determinada em certa medida pela categoria de modo, como veremos adiante.

Os clíticos posicionais de modo na e kot ocorrem no início da oração indicando não somente o modo gramatical do evento codificado, mas também o limite sintático a partir do qual se podem situar os elementos em destaque no nível pragmático. Assim, todo constituinte que aparece antes do marcador de modo está em foco (5-6).

$\begin{array}{llllll}\text { a. } & n a & \text { pa } & \text { [pĩ } & \text { ja }]_{\mathrm{SN}} & \text { pi } \\ & \text { RLS } & 1 & \text { pau } & \text { DEF } & \text { pegar }\end{array}$

'Eu peguei o pedaço de pau.'

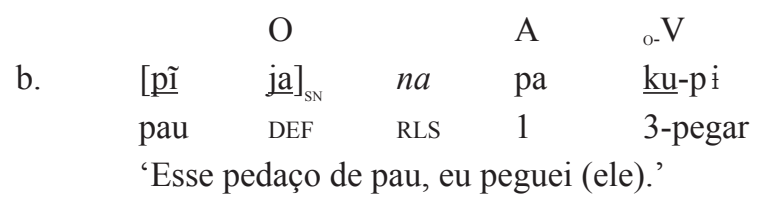

A $\quad$ O

(6)

\begin{tabular}{|c|c|c|c|}
\hline & A & $\mathrm{O}$ & \\
\hline$n a$ & pa & {$\left[\operatorname{prĩg}_{\Lambda}: \underline{\mathrm{ti}}\right.$} & $\underline{\mathrm{t} \Lambda \mathrm{n}}]_{\mathrm{SN}}$ \\
\hline RLS & 1 & bacuri & doce \\
\hline
\end{tabular}

'Eu estou fazendo doce de bacuri.' 

$\mathrm{O}$
A $\quad{ }_{0}-\mathrm{V}$
b.

\begin{tabular}{|c|c|c|c|c|}
\hline $\mathrm{O}$ & & & A & ${ }_{\mathrm{o}-\mathrm{V}} \mathrm{V}$ \\
\hline$\left[\operatorname{prrig}_{\Lambda}:\right.$ ti & $\underline{t[\Lambda \mathrm{n}}]_{\mathrm{SN}}$ & na & pa & $\underline{\varnothing}$-ipet \\
\hline ba & doce & RLS & 1 & 3 -fazer \\
\hline
\end{tabular}

Os exemplos (5-6) ilustram a estrutura básica da oração transitiva em Apinaje. $\mathrm{Na}$ ordem não marcada (5a, 6a), o verbo aparece no final da oração, imediatamente precedido de O. Quando o constituinte $\mathrm{O}$ se encontra sob ênfase pragmática, ele ocorre no início da oração, imediatamente precedente ao clítico de modo $(5 b, 6 b)$. Essa possibilidade de alternância repercute sobre a distribuição dos prefixos de terceira pessoa. Dos três alomorfes observados na Tabela 1, a forma $i$ - ocorre somente com nomes e, por essa razão, não será pertinente aqui. Já os outros dois alomorfes têm distribuição largamente motivada pela posição do constituinte $\mathrm{O}$ na oração.

No caso específico das raízes verbais monossilábicas, a ausência do sintagma nominal $\mathrm{O}$ em posição adjacente ao verbo determina a ocorrência obrigatória da forma $\mathrm{ku}$, que remete àquele constituinte (5a-b). ${ }^{10}$ No caso das raízes verbais de duas ou mais sílabas, a ocorrência obrigatória é do alomorfe zero e, no caso de a raiz ser iniciada em vogal, o prefixo relacional também se retira (6a-b), sinalizando a ausência do constituinte $\mathrm{O}$ naquela posição.

Nesses contextos de ênfase pragmática, obviamente é possível também que o foco recaia sobre A/S. Quando este argumento é de primeira ou segunda pessoa, o pronome pessoal ocorre duas vezes na oração, sendo uma delas preposta ao marcador de modo (7). Entre as duas ocorrências do pronome, nesse caso, a forma que se encontra sob a ênfase pragmática será enfatizada também no plano prosódico, através do desvozeamento da consoante inicial do morfema, enquanto a outra terá a consoante inicial foneticamente vozeada. Assim, os prefixos de primeira e segunda pessoa têm dois alomorfes cada, $[\mathrm{pa} \approx \mathrm{ba}]$ e $[\mathrm{ka} \approx$ ga], respectivamente, os quais são motivados pelos aspectos prosódicos característicos de cada contexto pragmático. 
$\begin{array}{llll}\mathrm{A}_{\#} & \mathrm{~A} & \mathrm{O} & \mathrm{V}^{11}\end{array}$

$\begin{array}{llllll}{[\mathrm{pa}]_{\#}} & n a & {[\mathrm{ba}]} & \operatorname{prĩg} \Lambda: \mathrm{ti} & \mathrm{t} \wedge \mathrm{n} & \mathrm{n} \text {-ipet } \int \\ 1_{\#} & \mathrm{RLS} & 1 & \text { bacuri } & \text { doce } & \text { PR-fazer }\end{array}$

'Eu é que estou fazendo doce de bacuri.'

Do mesmo modo, quando A/S é um argumento de terceira pessoa, um índice (sintagma nominal pleno ou pronominal) precede o marcador de modo e o outro ocorre após o clítico.

\begin{tabular}{|c|c|c|c|c|c|}
\hline $\mathrm{S}_{\mathrm{o}}$ & & & & ${ }_{0}-\mathrm{V}$ & \\
\hline [prĩr $\underline{\varepsilon}$ & ja] & na & kərmว̃ & 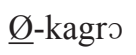 & ket $=$ nẽ \\
\hline criança & DEF & RLS & ainda & 3-quente & NEG \\
\hline
\end{tabular}

2 Classes de Verbos Segundo o padrão morfossintático de MarcaÇão ARGUMENTAL

O Apinaje exibe duas possibilidades de organização morfossintática para a expressão dos argumentos centrais da oração. Uma delas, conforme já visto nos exemplos (5-6), envolve a afixação de marcadores de pessoa diretamente ao verbo. A outra requer a afixação de marcadores de pessoa em posposições indicativas de casos oblíquos, sendo de ordem lexical essa combinação de verbos com posposições.

Esses dois padrões morfossintáticos de codificação das relações gramaticais, então, subcategorizam os verbos do Apinaje em duas classes. A primeira delas, aparentemente majoritária, consiste nos verbos que codificam atividades, ações, eventos, estados e mudanças de estado, e indicam seus argumentos centrais segundo o padrão recém-apresentado na primeira seção, em que existe a cisão entre os verbos intransitivos e descritivos, e a coexistência dos padrões nominativo e absolutivo.

Na outra classe, em que argumentos centrais são marcados por casos oblíquos, estão incluídos os verbos que codificam experiências sensoriais, emocionais, psicológicas e enunciativas - essencialmente, experiências e necessidades internas a Ego.

A marcação argumental, nos verbos dessa segunda classe, baseiase na estratégia característica dos verbos da primeira, porém acrescenta 
a esta um fator de complexidade semântica no plano conceitual, mais a necessidade de reorganização das relações gramaticais, em virtude da presença obrigatória da posposição.

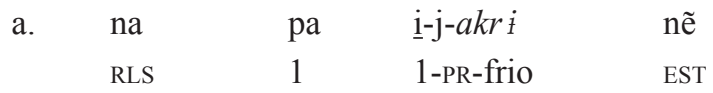

'Eu estou fria.'

$\begin{array}{llllll}\text { b. } & \text { na } & \text { pa } & \underline{\text { ing-mã }} & k r \dot{1} & \text { nẽ } \\ \text { RLS } & 1 & 1-D A T & \text { frio } & \text { EST }\end{array}$

'Eu estou com frio.'

Os exemplos em (9) ilustram a relação formal e semântica entre os predicados $a k r \dot{i}$ 'estar frio' e $m a ̃$ kri 'sentir frio'. Esta relação direta pode ser observada entre vários pares de verbos, nos dados, mas nem sempre é este o caso. A ausência de contrapartes formal e semanticamente relacionadas também é bastante comum (10-11).

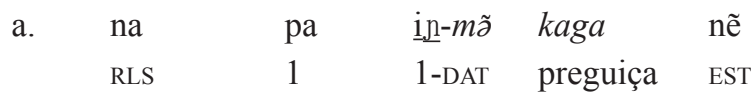

'Eu estou com preguiça.'

$\begin{array}{lllll}\text { b. } & * \text { na } & \text { pa } & \underline{\text { itf-kaga }} & \text { nẽ } \\ \text { RLS } & 1 & 1 \text {-preguiça } & \text { EST }\end{array}$

(11) a. na $\mathrm{ka} \quad \underline{\mathrm{a}}-m \tilde{a} \quad$ prom nẽ

RLS 2-DAT vontade EST

'Você está com fome.'

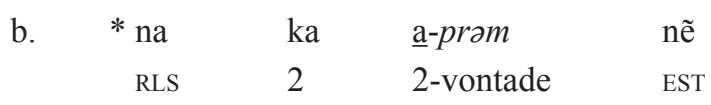

Os predicadores dessa classe podem ser relacionados também quanto à valência: um mesmo verbo pode variar em relação ao número de participantes, adicionando ainda mais complexidade à grade argumental e à grade conceitual nos diferentes usos (12). 
(12) Monovalente

\begin{tabular}{|c|c|c|}
\hline & Bivalente & \\
\hline 'estar com fome' & $\mathrm{S}_{\mathrm{A}}-m \tilde{\partial} \mathrm{O}-p r \tilde{m} m$ & 'querer $\mathrm{O}$ \\
\hline
\end{tabular}

Por outro lado, do mesmo modo que se observou a assimetria semântica ilustrada em (10-11), outros verbos bivalentes compartilham do mesmo padrão de marcação morfossintática acima, mas não têm uma contraparte monovalente correspondente (13).

(13)

'apetecer-se de O'
'antipatizar-se de O'
'afeiçoar-se de O'
'temer O'

* Monovalente

* $\mathrm{s}_{\mathrm{o}}-m \tilde{a} \Lambda \mu$

* $\mathrm{s}_{\mathrm{o}}-m \tilde{a}$ kure

* $\mathrm{s}_{\mathrm{o}}-m \tilde{\mathrm{k}} \mathrm{kin}$

* $\mathrm{S}_{\mathrm{A}}-m \tilde{u} \tilde{u} b a$

De qualquer modo, ainda que para fins metodológicos, é possível analisar esse subsistema de marcação argumental a partir da compreensão do primeiro, apresentado anteriormente. Cada padrão, na verdade, é específico de tipos distintos de predicados, categorizados nessa língua, em grande parte, com base nos aspectos semânticos da predicação inclusive no que tange ao papel semântico dos participantes envolvidos.

A esta altura, seria de se considerar a análise deste conjunto de predicadores conforme a noção extended predicates proposta por Dixon \& Aikhenvald (2000), que remete à ocorrência de argumentos centrais marcados por posposição em orações principais. Porém, neste ponto é preciso cautela, pois tal conceito prevê que "the types are clearly distinguishable since the $\mathrm{S}$ in a plain intransitive and the $\mathrm{S}$ in an extended intransitive have the same morphological marking and the same syntactic behavior, similarly for A and O" (p. 3).

Nos dados do Apinaje, não é isso o que ocorre. Os argumentos centrais dessa segunda categoria de predicados não necessariamente se comportam morfológica e sintaticamente da mesma maneira que os argumentos centrais das outras categorias de predicadores existentes na língua. Aliás, é justamente aí que reside o contraste entre categorias (9). Além disso, não existe necessariamente a contrapartida entre diferentes valências para um mesmo predicador, como se vê em (12-13). ${ }^{12}$ Assim, 
a definição proposta pelos autores parece não se aplicar aos dados do Apinaje.

Os verbos que pedem (ou aceitam) complemento oracional também pertencem a essa segunda categoria. Em geral, tais predicadores podem receber como argumentos tanto sintagmas nominais simples quanto orações completivas (14). Nesses casos, o verbo da oração subordinada ocorre em sua forma não finita.

\begin{tabular}{|c|c|c|c|c|c|}
\hline \multirow[t]{2}{*}{ (14) a. } & na & pa & іл-mә̃ & $\begin{array}{c}\mathrm{O} \\
{[\text { kag̃̃ }]}\end{array}$ & p-ũba \\
\hline & RLS & 1 & 1-DAT & cobra & PR-temer \\
\hline
\end{tabular}
b. do itf-katər=f $3^{13} \quad$ kõm $\left[\begin{array}{lllll}k u v \dot{t} & \text { mũj } & \tilde{\partial} & \underline{\text { apen }}\end{array}\right] \quad$ p-ũba mas 1-sair.NF-NMLZ.LOC 3.DAT fogo DIST LOC trabalhar.NF PR-temer 'Mas a minha mãe tem medo de trabalhar naquele fogão.'

\section{A FORMA NÃO FINITA DOS VERBOS}

As línguas da família Jê, conforme já reportaram vários autores, apresentam formas alternativas dos verbos cuja ocorrência se restringe a certas situações morfossintáticas, que variam desde as distinções de tempo e/ou aspecto da construção até o status do predicado como principal ou não dentro da sentença. Na literatura, tais formas têm sido denominadas "formas longas", em contraste com as "formas curtas ou breves" (SAntos, 1997; AmAdo, 2005; Miranda, 2009) ou "formas não finitas", em contraste com as "formas finitas" (OliveIRA, 2003, 2005; SALANOva, 2008).

A primeira denominação, "forma longa", aponta para a forma que o verbo assume, nessas circunstâncias, sendo ele geralmente acrescido de uma consoante ao final da base. Tais consoantes podem variar de verbo para verbo, não sendo facilmente analisáveis como um sufixo. Um problema dessa terminologia é que ela deixa de apontar as repercussões que a "forma longa" tem sobre a organização sintática do contexto em 
que aparece, restringindo-se apenas às características morfológicas do verbo.

A segunda denominação, "forma não finita", aponta para uma modificação no status morfossintático do verbo, já que, por definição, a forma não finita deixa de situar os argumentos do verbo no tempo e no espaço, dentro da cadeia de eventos do discurso, de modo que o predicado não finito é compreendido semântica e funcionalmente como um elemento constitutivo dentro da concepção de outro evento mais amplo.

Os traços morfológicos e o comportamento sintático das formas não finitas se distinguem de diversas maneiras das suas contrapartes finitas, tanto dentro de uma mesma língua quanto nas línguas do mundo. O que é comum, no entanto, é a característica funcional típica das formas não finitas de desempenharem papéis mais referenciais na gramática das línguas, enquanto as formas finitas tipicamente desempenham papel predicativo central na oração.

Em sua análise da língua Xavante, Georg Lachnitt (1988) interpreta este contraste em termos de "dois modos fundamentais" para os verbos: um codificado pela "forma verbal" e o outro pela "forma nominal", sendo esta última empregada quando a "ação do verbo está sob dependência de conjunção, posposição ou negação" (p. 83). Nesta análise do Apinaje, os termos finito e não finito serão adotados preferencialmente, pois captam de modo mais significativo as características sintáticas, semânticas e funcionais em questão.

A não finitude se manifesta no Apinaje como uma categoria flexional dos verbos, uma vez que todos, de quaisquer subcategorias observáveis na língua, apresentam uma contraparte não finita. Além disso, a forma não finita dos verbos exige a marcação de pessoa para todas as classes de verbos, inclusive para os intransitivos que, em oração principal, caracterizam-se pela impossibilidade de receberem a marca morfológica de pessoa, conforme ilustram (3a, 4b). Vale destacar que são os verbos intransitivos justamente os mais sujeitos às mudanças morfológicas em razão da não finitude, nos dados do Apinaje, e os verbos transitivos, depois deles. Os verbos descritivos muito raramente apresentam as modificações formais que afetam os primeiros. Em geral, essa é uma característica que põe em evidência o caráter marcado dos descritivos, dentro da classe dos verbos, bem como sua proximidade com os nomes, neste ponto. 
A forma não finita dos verbos pode se manifestar a partir de três estratégias: (a) adição de consoante final; (b) reestruturação silábica; e (c) alternância segmental, aplicadas simultânea ou individualmente à forma de base, tomada aqui como a forma finita.

Das três estratégias, a adição de consoante final à raiz verbal é a mais comum e se aplica àquelas terminadas em vogal. A consoante pode ser alveolar $[\mathrm{r}, \mathrm{n}, \mathrm{t}]$, palatal $[\mathrm{n}, \mathrm{j}]$ ou velar $[\mathrm{k}]$ e, em virtude da variedade articulatória e da ausência de fatores fonológicos claros que expliquem a distribuição desses segmentos, parece mais plausível entendê-los como modificações inerentes à base verbal, ou como sufixos de distribuição lexicalmente determinada - pelo menos em termos sincrônicos. Esse padrão se aplica, de forma predominante, a verbos transitivos e intransitivos, e menos comumente a verbos descritivos.

(15) Intransitivos

Forma finita Forma não finita

$\begin{array}{lll}\text { ape } & \mathrm{s}_{\mathrm{o}} \text {-jape-n } & \text { 'trabalhar' } \\ \text { atkẽ } & \mathrm{s}_{\mathrm{o}} \text {-pike-n } & \text { 'fazer piada' } \\ \text { api } & \mathrm{s}_{\mathrm{o}} \text {-japi-r } & \text { 'subir, escalar' }\end{array}$

Transitivos

Forma finita Forma não finita

gje o-gje-n 'guardar em orifício'

akje o-jakje-n 'furar'

atfw3 o-jatfw3-r 'botar de ponta cabeça'

As estratégias de ressilabificação e de mudança segmental são também bastante comuns entre os verbos intransitivos (16).

(16) Intransitivos

\begin{tabular}{|c|c|c|}
\hline $\begin{array}{l}\text { Forma finita } \\
\text { amf̂ra }\end{array}$ & $\begin{array}{l}\text { Forma não finita } \\
\mathrm{s}_{\mathrm{o}} \text {-jamra }\end{array}$ & 'gritar' \\
\hline twa & $\mathrm{S}_{\mathrm{o}}-\mathrm{v} 3 \mathrm{r}$ & 'banhar-se' \\
\hline gõr & $s_{0}-$ nõt & 'dormir' \\
\hline bur & $s_{0}-b 3 r$ & 'chorar' \\
\hline t $\mathrm{a}$ & $s_{0}-t \sqrt{3 m}$ & 'ficar de pé' \\
\hline
\end{tabular}


De modo geral, as formas não finitas dos verbos ocorrem em qualquer situação de subordinação, desde a derivação de nomes deverbais até a expressão de orações relativas, completivas, adverbiais etc. Em todas essas circunstâncias, a marcação argumental nos verbos seguirá o padrão absolutivo, sem exceções.

\section{A CODIFICAÇÃO DAS RELAÇÕES GRAMATICAIS NOS COMPLEMENTOS ORACIONAIS DO APINAJE}

No Apinaje, construções envolvendo complementos oracionais são menos abundantes do que no Português, por exemplo. Muito mais comum é a justaposição de orações independentes, de modo a expressar o equivalente funcional das construções completivas da nossa língua.

Nos dados analisados, há um pequeno conjunto de verbos que selecionam complementos oracionais, porém tais complementos só ocorrem em posição de objeto. Não há ocorrência de complementos em posição sintática de sujeito, no corpus.

Todos os verbos que pedem ou aceitam orações completivas marcam argumento central com posposição. Na construção sintática, o padrão da oração principal se mantém, no que diz respeito à presença dos clíticos iniciais e pronomes independentes, bem como a posição final do verbo. Dentro da oração subordinada, as relações gramaticais serão reorganizadas a partir do fato de que a forma não finita segue o padrão absolutivo, associado às possibilidades lógicas de correferencialidade entre o argumento A da oração principal e o argumento $\mathrm{A} / \mathrm{S}$ da oração subordinada.

Em (17), o exemplo ilustrativo é o verbo transitivo mã pũba, que recebe sintagma nominal simples, mas também aceita complemento oracional. Note-se que o complemento ocorre na mesma posição sintática de $\mathrm{O}$, como atesta o prefixo relacional no verbo (17a-b). Dentro da subordinada, o argumento $\mathrm{O}$ aparece adjacente ao seu predicador, em sua forma não finita (17b).

\begin{tabular}{|c|c|c|c|c|c|}
\hline \multirow[t]{2}{*}{ (17) } & a. & na & $\begin{array}{l}\text { A } \\
\text { in-mã }\end{array}$ & $\begin{array}{c}\mathrm{O} \\
{[[\mathrm{kuke} n]}\end{array}$ & $\begin{array}{l}\mathrm{V} \\
\mathrm{p} \text {-ũba] }\end{array}$ \\
\hline & & RLS & 1-DAT & cotia & PR-temer \\
\hline
\end{tabular}




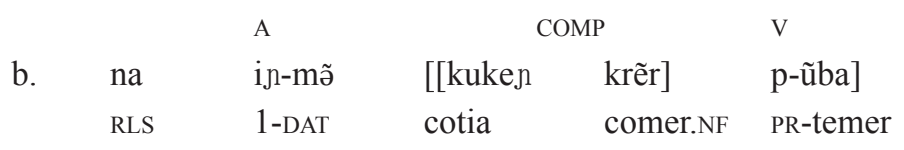

'Eu tenho medo de comer cotia (e ficar doente, por exemplo).'

Nos exemplos em (18), o complemento oracional é um verbo descritivo, cujo argumento $S$ é correferencial com $A$ da oração principal. A forma não finita do verbo vem marcada com o prefixo de primeira pessoa, em posição sintática de complemento.

$\begin{array}{llll} & \mathrm{S} & \mathrm{S}_{\mathrm{o}} \\ \text { a. } & \text { na } & \text { pa } & \text { itf-oprere } \\ & \text { RLS } & 1 & 1 \text {-bravo }\end{array}$

'Eu estou bravo!'
A COMP V
$\begin{array}{lll}\text { b. } \quad \text { in-mã } & {[[i t \text {-oprere }]} & \text { p-ũba }] \\ \text { 1-DAT } & \text { 1-bravo } & \text { PR-temer }\end{array}$

'Eu tenho medo de ficar valente (se eu beber, por exemplo).'

Finalmente, em (19), o verbo não finito é transitivo e o argumento A da oração principal e da subordinada não são correferenciais. Nesse caso, o argumento A, dentro da oração subordinada, é ergativo, completando, assim, o conjunto das possibilidades existentes no sistema de alinhamento da língua Apinaje.
A
a. mekarõ na ing-irã nẽ
espírito RLS 1-espiar EST
'O espírito fica me espiando.'

A

b. $\quad \underline{\text { in-mã }}$
COMP<smiles>[AlH2]</smiles>

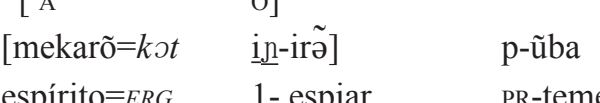

'Eu tenho medo de os espíritos ficarem me espiando.' 
A ergatividade é expressa internamente à oração completiva através dos morfemas posposicionais $t \varepsilon$ e $k \partial t$, cuja ocorrência é determinada pela distinção de pessoa do referente. A forma $t \varepsilon$ atende aos sintagmas nominais ergativos de primeira e segunda pessoa, e a forma $k s t$, aos de terceira pessoa. Por se tratar de posposição, o marcador ergativo pode receber os prefixos pessoais, mas a forma de terceira pessoa é supletiva.

É plausível analisar a forma supletiva como diacronicamente originária de uma forma prefixada em $k u$-, constituindo assim o paradigma $* i f-t \varepsilon, a-t \varepsilon, k u-t \varepsilon$. O prefixo de terceira pessoa teria, dessa forma, se incorporado à estrutura silábica da raiz que, por sua vez, perde a vogal final, de modo que de duas sílabas resta somente uma, CVC. A vogal da forma reduzida assimila o traço [- alto] da vogal perdida

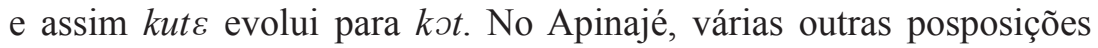
apresentam também a forma supletiva de terceira pessoa conforme esse padrão, todas iniciadas em $/ \mathrm{k} /$.

\section{Conclusão}

O sistema de marcação pessoal do Apinaje revela um tipo de alinhamento que integra os padrões nominativo, acusativo, absolutivo e ergativo. O padrão ergativo é restrito aos casos de subordinação em que o sujeito da oração matriz não é correferencial com o argumento A da oração completiva.

Dentro da oração subordinada, a ergatividade é marcada por uma posposição cliticizada ao sintagma nominal A, enquanto o argumento $\mathrm{O}$ é codificado conforme o padrão absolutivo pelos prefixos pessoais, de ocorrência obrigatória nas formas não finitas dos verbos.

É possível contrastar simetricamente o padrão ergativo/ absolutivo, restrito às orações subordinadas, com o padrão nominativo/ acusativo, característico das orações principais. Como já foi visto, o padrão nominativo se manifesta através dos pronomes independentes. Porém, dentre os prefixos pessoais, existe um morfema cuja distribuição também se restringe ao contexto das orações principais: o prefixo de terceira pessoa $\mathrm{ku}$ - (ver nota 11$)$.

Uma vez que jamais aparece em contextos de subordinação, conforme sugerem os dados, o morfema $k u$ - não compõe o paradigma 
pessoal das formas não finitas juntamente com os demais prefixos, daí se conclui que o prefixo $k u$ - não faz parte do paradigma absolutivo. Em vez disso, contrasta-se com este, constituindo por si só um paradigma acusativo, o qual se comunica diretamente com o padrão nominativo expresso pelos pronomes pessoais nas orações independentes. Assim, o paradigma nominativo/acusativo ocorre nas orações principais, enquanto o paradigma ergativo/absolutivo ocorre nas subordinadas.

Tal constatação não extingue nem nulifica as complexidades já atestadas nas orações simples em virtude da cisão entre os verbos monovalentes e da existência dos não canônicos; em vez disso, ela chama a atenção para a coexistência dessas complexidades. É necessário observar ainda que o morfema $k u$ - pode se prefixar a posposições, o que torna ainda mais interessante a questão sobre qual teria sido a trajetória percorrida por esse prefixo até alcançar o status de morfema acusativo dentro do paradigma verbal do Apinaje, a ser investigada.

A outra observação importante é a de que a manifestação do alinhamento ergativo/absolutivo está condicionada à ocorrência da forma não finita do verbo, o que parece ser uma característica típica da família Jê. Alguns autores já lançaram hipóteses sobre o status nominal dessas construções, partindo do raciocínio de que as formas não finitas codificam uma visão referencial do evento e operam como constituintes nominais dentro de uma predicação plena.

Em sua análise do Mẽbengokre, Salanova (2008) tece um paralelismo entre as construções ergativas, baseadas nos verbos não finitos, e as construções genitivas baseadas em nomes relacionais. $\mathrm{O}$ autor afirma que, tanto nas construções não finitas quanto nas construções relacionais, "o sintagma nominal absolutivo aparece sempre ao lado do núcleo, e no caso dos pronomes, se integra morfologicamente a este," e que "o argumento absolutivo é obrigatório". Assim, com base nas evidências estruturais, o autor argumenta que se trata de uma mesma construção em ambos os casos. As formas verbais não finitas podem ser vistas, portanto, como nominalizações de evento ou de participantes centrais, assumindo propriedades referenciais, posto que

as formas nominais dos verbos nunca denotam proposições; elas se referem aos eventos no seu desenrolar, ou aos participantes nos eventos. Supõe-se que como as orações têm que ser proposições, as 
nominalizações são, como orações, incompletas. Por isto elas normalmente só aparecem encaixadas. (SAlANOva, 2008, p. 120)

Em sua proposta sobre a análise da ergatividade nas línguas Jê setentrionais, Eduardo Rivail Ribeiro (2003) ${ }^{14}$ chama a atenção para o fato de que, translinguisticamente, existe uma tendência para que nomes deverbais reelejam as relações gramaticais de caso absolutivo como seus argumentos obrigatórios, e cita exemplos do Português, como: "é proibida a entrada de menores" ( $\mathrm{s}_{0}$ ) e "é proibido o consumo de bebidas alcoólicas" (o), além de apontar casos semelhantes no Inglês, no Latim e no Karajá.

No caso do Apinaje, as evidências apontam para as mesmas conclusões gerais de que o sistema ergativo se manifesta gramaticalmente nos contextos de subordinação e que as orações completivas, encaixadas na posição de objeto, certamente demonstram características nominais, tanto no plano formal quanto no funcional. Ainda assim, defendo o ponto de que as nominalizações sintáticas observadas no Apinaje apresentam características próprias que as distinguem, dentro da categoria dos nominais, apesar dos paralelismos no plano morfológico e quanto à função referencial típica dos nomes. Maiores detalhes sobre este ponto serão desenvolvidos em outra oportunidade.

Os fatos e a análise apresentados neste artigo colocam em evidência as características tipológicas da codificação das relações gramaticais na língua Apinaje, tanto no contexto das orações independentes quanto no das subordinadas, mas não explica o porquê de as construções ergativas/absolutivas serem formalmente semelhantes às construções nominais. Esse tema fica reservado para um novo trabalho, dedicado ao estudo das nominalizações no Apinaje, na esperança de poder contribuir para a análise das motivações funcionais e diacrônicas que conduzem a gramática da ergatividade nas línguas da família Jê.

The CODING OF GRAMMATICAL RELATIONS IN APINAJE COMPLEMENT CLAUSES

\section{ABSTRACT}

The coding of grammatical relations in languages of the Jê family displays great morphosyntactic complexity manifested in main, as well as in subordinate 
clauses. In Apinaje, the coding of core arguments in simple clauses combines a nominative pattern, manifested by means of independent pronouns, and an absolutive pattern, expressed by person prefixes attached to verbs. Additionally, a certain class of verbs marks core arguments with oblique postpositions, thus displaying a noncanonical pattern; complement-taking verbs belong in this category. In the context of complementation, the ergative alignment will occur depending on the correferenciality conditions between main and subordinate clause subjects.

KeY wORDS: Apinaje, person marking, grammatical relations, complementation.

\section{LA CODIFICACIÓN DE LAS RELACIONES GRAMATICALES EN LAS ORACIONES COMPLETIVAS DEL APINAJE}

\section{RESUMEN}

La codificación de las relaciones gramaticales en las lenguas de la familia Je se caracteriza por una gran riqueza morfosintáctica manifestada tanto en las oraciones independientes como en los contextos de subordinación, aunque con más profusión aún en éstos últimos. Em Apinaje, el marcaje de los argumentos en las independientes exibe un patrón nominativo, expresado por pronombres, y absolutivo, expresado por prefijos personales. En verbos con marcaje argumental no canónico, algunos argumentos nucleares se marcan mediante portposiciones oblicuas. Pertenecen a esa clase de verbos los que admiten cláusulas completivas. En este contexto de subordinación se presenta alineamiento ergativo, el cual es determinado por las condiciones de correferencialidad entre el sujeto de la cláusula principal y el de la subordinada.

Palabras Clave: Apinaje, categoría de persona, relaciones gramaticales, oraciones completivas.

\section{Notas}

1 A pesquisa linguística que permitiu a produção deste artigo foi possível graças à receptividade, generosidade e cordialidade do povo Apinaje, a quem expresso aqui os meus mais sinceros agradecimentos, em particular, ao povo das aldeias São José e Patizal. Agradeço a Greri Júlia Laranja (in memoriam) e Kojkoti Iraci Dias Apinaje, minhas nãs, que tão carinhosamente me acolheram no seio da comunidade Apinaje, compartilhando comigo 
suas histórias, seus conhecimentos, sua sabedoria, sua alegria e muito mais; a Amxi Creuza Fernandes Apinaje e Ire Rita Dias Laranja, minhas tõt', pela assessoria e consultoria linguística impecáveis, pela amizade e pela paciência em me ensinar a enxergar o mundo pelos olhos dos Apinaje. Agradeço ainda a dois pareceristas anônimos pelas críticas e sugestões que contribuíram para o refinamento do texto final deste artigo. Quaisquer erros que porventura tenham permanecido são de minha inteira responsabilidade.

2 A língua Apinaje pertence ao ramo Setentrional da família linguística Jê. Atualmente é falada por mais de 1600 pessoas no território Apinaje, tradicionalmente localizado na região do Bico do Papagaio, confluência dos rios Araguaia e Tocantins. A Terra Indígena Apinaje situa-se na região de Tocantinópolis (TO). Neste artigo, o nome da língua é grafado de acordo com as regras do sistema ortográfico Apinaje.

3 Os dados apresentados neste artigo são oriundos principalmente do falar dos Apinaje das Aldeias São José e Patizal, e foram obtidos em pesquisa de campo realizada em diferentes visitas à Terra Indígena Apinaje, no período entre 1995 e 2000, ao longo do qual foi possível criar uma base de dados fonográficos e imagéticos consistindo de diversos tipos de manifestações verbais em Apinaje - em particular, narrativas, instruções, verbalizações cerimoniais. A partir da transcrição desses materiais, com a assistência das consultoras de língua Apinaje, desenvolveu-se ainda um arquivo de verbos com o registro dos respectivos paradigmas flexionais - vários exemplos a seguir vêm de paradigmas eliciados como esses. Todo o levantamento dos dados linguísticos fundamentou-se no fato de que o contexto discursivo é relevante para a compreensão dos fenômenos existentes nas línguas, de modo que a coleta desses paradigmas se deu no âmbito da discussão e análise das narrativas junto com as consultoras linguísticas.

4 A distribuição desses morfemas numerais revela sua dependência relativa ao marcador de pessoa, ao mesmo tempo em que coloca em evidência o fato de que não ocupam uma posição fixa, já que mẽ e va seguem o pronome, mas precedem o prefixo pessoal. Pode-se analisá-los, portanto, como clíticos, pois, embora tenham distribuição restrita à "órbita" dos marcadores de pessoa, não são efetivamente afixados a eles.

5 O sistema de transcrição adotado neste artigo, para a apresentação dos dados, é essencialmente fonêmico, empregando símbolos do Alfabeto 
Fonético Internacional, exceto pela representação dos fones oclusivos pré-nasais [mb, nd, gg], transcritos aqui com os símbolos $b, d$, $g$. Os fones pré-nasais do Apinaje foram originalmente analisados por Patricia Ham (1961) como alofones das suas respectivas contrapartes nasais. Contudo, a partir da nossa base de dados, foi possível observar exemplos que parecem contrariar essa interpretação (Oliveira, 2005). Por esse motivo, opto por representá-los de forma distinta aqui.

6 Abreviações: 1 'primeira pessoa'; 2 'segunda pessoa'; 3 'terceira pessoa'; ACUS 'acusativo; CLT 'coletivo'; CMPL 'aspecto completivo'; DAT 'dativo'; DEF 'definido'; DIST 'distal'; DU 'dual'; ERG 'ergativo'; EST 'estativo'; IRLS 'irrealis; LOC 'locativo'; MOV 'movimento'; NEG 'negação'; PL 'plural'; PR 'prefixo relacional; RLS 'realis'; SN 'sintagma nominal'.

7 Akũdo pertence à classe dos verbos ativos, os quais não recebem prefixos pessoais em oração principal. Ver exemplo (4.b) adiante.

8 Neste contexto, a letra maiúscula $\mathrm{C}$ representa a existência de uma consoante cuja forma fonética dependerá do ambiente fonológico em que ocorre o prefixo. Em todos os alomorfes, no entanto, a consoante em questão se caracteriza pelo traço [palatal].

9 O pronome de terceira pessoa irrealis coincide em forma com o demonstrativo e marcador definido $j a$.

10 Os dados do corpus indicam que o prefixo $\mathrm{ku}$ - é um marcador acusativo de terceira pessoa, pois sua ocorrência se restringe à posição sintática de $\mathrm{O}$ nas orações transitivas, inclusive, não ocorrendo em contextos de subordinação.

11 Onde "\#” indica pausa e/ou ênfase entoacional sobre o constituinte em questão.

12 Ver maiores detalhes em Oliveira (2005), capítulos 3 e 4.

13 Em Apinaje, 'mãe' (literalmente: ‘o lugar de onde eu saí').

14 Trabalho apresentado no II Encontro do Grupo de Estudos Linguísticos do Centro-Oeste (GELCO), ocorrido em Goiânia, de 8 a 10 de outubro de 2003. Disponível em: http://ribeiro.wdfiles.com/local--files/ paper\%3Aergatividade/ergatividade.pdf. Acesso em: 8 dez. 2014. 


\section{REFERÊNCIAS}

Amado, R. de S. Descrição das formas verbais longas e breves do Pykobjê: uma contribuição para o estudo dos verbos nas línguas Jê. Revista do GEL, Araraquara, v. 2, p. 83-105, 2005.

Dixon, R.; Aikhenvald, A. Introduction. In: . Changing valency: case studies in transitivity. Cambridge: Cambridge University Press, 2000. p. 1-28. Givón, T. Syntax. 2 volumes. Amsterdam/Philadelphia: John Benjamins, 2001. Haм, P. Apinayé phonemic statement. Arquivo Linguístico, 106. Brasília: Summer Institute of Linguistics, 1961.

Lachnitt, G. Gramática Xavante (Damreme'uwaumramidzé). Campo Grande: Missão Salesiana de Mato Grosso, 1988.

Miranda, M. G. Investigando as formas verbais longas em Krahô. In: CONGResso internacional da abralin vi, 2009, João Pessoa. Anais... (v. 2), João Pessoa: ABRALIN, 2009. p. 3858-3965.

Noonan, M. Complementation. In: SHopen, T. Language typology and syntactic description: complex constructions. 2. ed. v. II. Cambridge: Cambridge University Press, 2007. p. 52-150.

Oliveira, C. C. de. Lexical categories and the status of Descriptives in Apinaje. International Journal of American Linguistics, v. 69, n. 1, p. 243-274, 2003.

. The language of the Apinaje people of Central Brazil. Tese (Doutorado em Linguística) - Linguistics Department, University of Oregon, Eugene, 2005.

Salanova, A. P. Uma análise unificada das construções ergativas do Mẽbengokre. Amerindia, v. 32, p. 109-134, 2008.

Santos, L. C. dos. Descrição de aspectos morfossintáticos da língua Suyá (Kisêdjê), família Jê. Tese (Doutorado em Linguística)-Centro de Comunicação e Expressão, Universidade Federal de Santa Catarina, Florianópolis, 1997.

Recebido em $1^{\circ}$ de julho de 2014

Aceito em 14 de setembro de 2014 